\title{
Authors' Response to the Review Comments
}

Journal: $\quad$ Journal of Non-Crystalline Solids

Manuscript \#: $\quad$ NOC-D-16-00511

Title of Paper: $\quad$ Synthesis, physico-chemical and biological characterization of strontium- and cobalt substituted bioactive glasses for bone tissue engineering

We made changes in the order of the authors. Please consider below order.

Authors: Saeid Kargozar; Nasrin Lotfibakhshaiesh; Jafar Ai; Ali Samadikuchaksaraie; Roberrt G. Hill; Priyen A. Shah; Peiman Brouki Milan; Masoud Mozafari; Mohammadhossein Fathi; Mohammad Taghi Joghataei

\section{Date Sent: $\quad$ 19/JUL}

We appreciate the time and efforts by the editor and referees in reviewing this manuscript. We have addressed all issues indicated in the review report, and believed that the revised version can meet the journal publication requirements. 


\section{Response to Comments from Reviewer 1}

We greatly appreciate the reviewer's efforts to carefully review the paper and the valuable suggestions offered.

\section{Comment 1:}

No need for separating fig. 3 and 4

Response:

As suggested by the reviewer, we merged the Fig.3 and Fig.4 as a single Figure (new Fig.3) and also the caption was correct.

\section{Comment 2:}

The same also for fig. 5 and 6

Response:

These figures were also jointed (new Fig.4) as suggested by the reviewer.

\section{Comment 3:}

$>\quad$ Table I and III can be combined together

\section{Response:}

The two tables (I and III) were merged as suggested by the reviewer.

\section{Comment 4:}

$>\quad$ The authors claimed that the presence of Sr and Co ions in the glass composition causes a delay in the formation of HCA layer. An explanation for the above statement is required particularly the authors claimed that the apatite layer has fully developed after immersion in SBF for 3, 7 and 14 days. 


\section{Response:}

We appreciate the reviewer's comment. The mentioned sentence was deleted. These glasses form apatite fairly quickly. (Page 12, second paragraph, last sentence was deleted)

\section{Comment 5:}

$>$ In Fig. 4 caption the split band is seen around 586 but in the figure itself the arrow refers to 568. This requires correction throughout the whole manuscript. Also the unit wavelength should be written after the number.

\section{Response:}

In the revised manuscript, we changed 586 to $568 \mathrm{~cm}^{-1}$ and the unit wavelength was added after the number.

\section{Comment 6:}

The authors highlighted that Sr-containing glasses ( $\mathrm{Sr}$ and $\mathrm{Sr}-\mathrm{Co}$ ) showed higher ALP activity than other glasses but the difference between Sr- and Sr-Co glass should be also discussed.

Response:

As suggested by the reviewer, the difference of ALP level between Sr- and Sr-Co glass was discussed in discussion section. (Page 14, second paragraph, line 9,)

\section{Response to Comments from Reviewer 2}

We appreciate the comment by reviewer- 2 . 
Comment 1:

$>$ Surface area or porosity measurements, if it is feasible, may be give also more information about these bioactive glasses

Response:

We have provided particle size data but regarding to the porosity, it is not really relevant for melt-derived glasses as opposed to sol gel glasses.

\section{Response to Comments from Reviewer 3}

We greatly appreciate the reviewer's efforts to carefully review the paper and the valuable suggestions offered.

\section{Comment 1:}

fully characterization' should be 'full characterization'

$>$ Indicate the elements $(\mathrm{Sr}, \mathrm{Co})$ without specifying the ionic charge, or replace the term 'elements' with 'ions'.

Response:

The change and correction was done. (Page 2, lines 3) (Page 2, line 4) (Page 4, lines 12 and 14)

\section{Comment 2:}

$>$ Citation of this review paper on ion-doped bioglasses in the Introduction is recommended: Biomaterials 32 (2011) 2757-2754.

Response:

The mentioned paper was cited in the introduction section. (Page 3, second paragraph, line 3) 


\section{Comment 3:}

$>$ I agree that bioglass-based products have a great potential for treating bone defects in an ageing population; you could cite the following paper to support your statement: Journal of the European Ceramic Society 36 (2016) 2175-2182.

\section{Response:}

The paper was cited in the manuscript as suggested by the reviewer. (Page 3, first paragraph, line 9)

\section{Comment 4:}

Desides bone repair, there are new emerging applications of bioglasses in other medical areas, in this regard you could cite the following papers:

\# Journal of Biomedical Materials Research A 103 (2015) 1259-1275.

\# Journal of Non-Crystalline Solids 432 (2016) 15-30.

\section{Response:}

We cited both of the papers in the manuscript. (Page 3, first paragraph, line 11)

\section{Comment 5:}

$>$ Have you checked rhodium contamination (from the crucible) in your glasses (e.g. by $\mathrm{XRF}$ or EDX)?

\section{Response:}

We haven't checked rhodium. But very small amounts of rhodium in bioactive glasses in the ppm range result in a yellow/orange hue and all the glasses were completely clear. 


\section{Comment 6:}

$>$ What's the control used in biological testing? Medium without bioglass? Perhaps I lost this detail.

Response:

In biological tests, medium without the bioglass was considered as a control group and was added in the manuscript. (Page 8, line 1)

\section{Comment 7:}

$>$ Ion release study (for example by means of ICP) should be performed, if possible.

\section{Response:}

We strongly agree this comment, but it is not possible.

\section{Comment 8:}

$>$ Check the reference list carefully and make uniform the style.

\section{Response:}

The reference list was checked again and became uniform. (Page 16)

\section{Comment 9:}

$>$ Highlights are lacking, please add.

\section{Response:}

Highlights were prepared. 


\section{Synthesis, physico-chemical and biological characterization of strontium and cobalt substituted bioactive glasses for bone tissue engineering}

Saeid Kargozar ${ }^{1}$, Nasrin Lotfibakhshaiesh ${ }^{1 *}$, Jafar $\mathrm{Ai}^{1}$, Ali Samadikuchaksaraie ${ }^{2,3,4}$, Roberrt G. Hill $^{5}$, Priyen A. Shah ${ }^{6}$, Peiman Brouki Milan ${ }^{1}$, Masoud Mozafari ${ }^{7}$, Mohammadhossein Fathi ${ }^{8}$, Mohammad Taghi Joghataei ${ }^{1,2, *}$

1. Department of Tissue Engineering and Applied Cell Sciences, School of Advanced Technologies in Medicine, Tehran University of Medical Sciences, Tehran, Iran

2.Cellular and Molecular Research Center, Iran University of Medical Sciences, Tehran, Iran.

3. Department of Tissue Engineering and Regenerative Medicine, Faculty of Advanced Technologies in Medicine, Iran University of Medical Sciences, Tehran, Iran;

4. Department of Medical Biotechnology, Faculty of Allied Medicine, Iran University of Medical Sciences, Tehran, Iran

5. Unit of Dental Physical Sciences, Barts and The London School of Medicine and Dentistry, Queen Mary University of London, Mile End Road, London E1 4NS, United Kingdom

6. The London School of Medicine and Dentistry, Institute of Dentistry, London, United Kingdom

7. Bioengineering Research Group, Nanotechnology and Advanced Materials Department, Materials and Energy Research Center (MERC), Tehran, Iran.

8. Biomaterials Group, Department of Materials Engineering, Isfahan University of Technology, Isfahan, Iran

Correspondence to:

1-M. T. Joghataei; e-mail: mt.joghataei@yahoo.com

2- N. Lotfibakhshaiesh; email: n.lotfiba@gmail.com

Department of Tissue Engineering and Applied Cell Sciences, Faculty of Advanced Technologies in Medicine, Tehran University of Medical Sciences, Tehran, Iran 


\begin{abstract}
Due to their vast potential for repair and regeneration, different types of bioactive glasses (BGs) have been widely studied for bone tissue engineering. In this study, different groups of melt-derived bioactive glasses containing strontium $\left(\mathrm{Sr}^{2+}\right)$ and cobalt $\left(\mathrm{Co}^{2+}\right)$ ions have been designed to investigate their potential effect on increasing cell osteogenic activity. After full characterization of the synthesized bioactive glasses, they were evaluated for apatite forming ability in simulated body fluid (SBF) after different time intervals. The glasses have been examined for cell attachment and cell cytotoxicity plus their influence on osteogenic activity of the cells was analyzed by alkaline phosphatase assay (ALP) and alizarin red staining. The results show that the samples are in glassy state before immersion in SBF and an apatite-like layer has formed on the surface of SBF-immersed samples after 3, 7 and 14 days. In vitro experiments demonstrated that the incorporation of $\mathrm{Sr}^{2+}$ and $\mathrm{Co}^{2+}$ in the glass composition significantly promote osteogenic activity of human osteosarcoma cells without any cytotoxicity effect.
\end{abstract}

Keywords: Bone Tissue Engineering; Bioactive glass; Strontium; Cobalt; in vitro study 


\section{Introduction}

Based on the worldwide spread of bone injuries and disorders, bone regeneration has become increasingly important. It is predicted that prevalence of bone defects requiring treatment will double by 2020 , due to an aging population, accidents, congenital genetic abnormalities and obesity [1]. Traditional approaches including autograft, allograft and xenograft are coupled with many restrictions such as donor site morbidity, rejection and disease transmission [2, 3]. Therefore, many types of natural and synthetic biomaterials have been proposed as bone substitutes to reconstruct and restore the native function [4-6]. Among the different biomaterials, bioactive glasses have gained much attention for bone tissue engineering applications due to their superior advantages, such as osteoinductivity and osteoconductivity over conventional bioceramics [7-12]. Today bioactive glasses are used in various applications as a bone blocks, cements and bone void fillers for treatment of disorders such as fractures, bone cysts and tumors [13-15].

In recent years, various inorganic ionic species are added to the initial composition of bioactive glasses $\left(\mathrm{SiO}_{2}, \mathrm{CaO}, \mathrm{Na}_{2} \mathrm{O}, \mathrm{P}_{2} \mathrm{O}_{5}\right)$ to further improve their biological properties, such as better angiogenesis (blood vessel formation) and accelerating wound healing [16]. Among ionic species, strontium $\left(\mathrm{Sr}^{2+}\right)$ is one of the most attractive ions used to improve osteogenic activity of BGs. This metal ion has been used for many years for treatment of osteoporosis, in the form of Strontium Ranelate (SrR) [17-20]. In several prior studies, it has been shown that $\mathrm{Sr}^{2+}$ has a significant role in increasing bone density and reducing fracture risk in humans and other

mammals [21-24]. $\mathrm{Sr}^{2+}$ ions also accelerates bone regeneration through a binary approach in which deposition of new bone increased by osteoblasts and simultaneously resorption of bone is reduced by osteoclasts $[25,26]$. Furthermore, angiogenesis plays a key role in expediting new 
bone formation, which is regulated by several growth factors (such as vascular endothelial growth factor) and especially conditions (such as Hypoxia) [27]. To induce angiogenesis through hypoxia, several studies have been conducted in vitro and in vivo [28-31]. Cobalt $\left(\mathrm{Co}^{2+}\right)$ as a metal ion is frequently considered for induction hypoxia condition. It has been previously documented that $\mathrm{Co}^{2+}$ induces hypoxia through up-regulation of HIF-1 $\alpha$ and vascular endothelial growth factor (VEGF) genes in primary osteoblasts and osteoblastic cell lines [32-36]. Meanwhile, it has been shown that the HIF-1 pathways accelerate bone regeneration by increasing angiogenesis, stem cell differentiation, and fracture repair [20,36]. As a result, it has

been suggested that $\mathrm{Co}^{2+}$-releasing bioactive glasses can simulate a hypoxic condition which is then used for activation angiogenesis-related genes and thereby promoting bone tissue regeneration [29, 30, 37, 38]. Previously, Azevedo, et al [31] synthesized $\mathrm{Co}^{2+}$-containing bioactive glass particles with focus on angiogenesis. Although recent studies provide new information about the effect of $\mathrm{Sr}^{2+}$ and $\mathrm{Co}^{2+}$ in vitro and in vivo, the influence of the simultaneous use of these two ions on structural, physico-chemical and biological activity of glasses is still not well understood. Therefore, the main goal of this study was to synthesize bioactive glasses using these two ions in the composition for the improvement of biological and osteogenesis activities. In addition, more multicomponent BGs may inhibit the crystallization of the glasses and facilitate the fabrication of these glasses into porous scaffolds by viscous flow sintering.

\section{Materials and methods}




\subsection{Glass synthesis}

The BGs were synthesized based on a multi-component $\mathrm{SiO}_{2}-\mathrm{P} 2 \mathrm{O}_{5}-\mathrm{CaO}-\mathrm{SrO}-\mathrm{Na}_{2} \mathrm{O}-$ $\mathrm{MgO}-\mathrm{ZnO}-\mathrm{K}_{2} \mathrm{O}$ system using a melt-quench approach. All of the components were purchased as analytical grade (Sigma-Aldrich, UK). The components were melted in a platinum-rhodium crucible for $1.5 \mathrm{~h}$ at $1400^{\circ} \mathrm{C}$ in an electric furnace (Lenton, Hope Valley, UK). After melting, the glasses were immediately quenched rapidly into water to prevent crystallization. The dried glasses were ground using a vibratory puck mill (Gyro Mill, Glen Creston, London, UK) for 15 min and sieved to a particle size below $38 \mu \mathrm{m}$. The different groups were named as $\mathrm{Ca}, \mathrm{Sr}, \mathrm{Ca}-$ Co and Sr-Co and their compositions are given in Table I.

\subsection{Glass characterization}

\subsubsection{Differential scanning calorimetry (DSC)}

Differential scanning calorimetry (DSC) was used to evaluate glass transition temperature of the samples. For this purpose, the glass powder samples $(50 \mathrm{mg})$ were placed in an inert platinum crucible. An analytical grade alumina powder was used as a reference material. The experiments were carried out in air, using a Stanton-Redcroft DSC 1500 (PL Thermal Sciences, Epsom, UK) at a constant heating rate of $20 \mathrm{~K} \mathrm{~min}^{-1}$ up to a maximum temperature of $1050{ }^{\circ} \mathrm{C}$.

\subsubsection{X-ray diffraction (XRD)}

The crystal structure of the samples was determined by X-ray diffraction (XRD) (Philips PW1700 series Automated Powder Diffractometer). The samples were evaluated before and after immersion in simulated body fluid (SBF) fusing an X-ray powder diffractometer equipped with a 
monochromatized $\mathrm{Cu}-\mathrm{K} \alpha$ radiation $(\Theta=1.54056 \AA)$ in the $2 \Theta$ range [39] with a step size of $0.04^{\circ}$

\subsubsection{FTIR analysis}

To analyze the samples before and after soaking in SBF, the dried powders were analyzed using Fourier-transform infrared spectroscopy (FTIR) (NICOLET IS10 FT-IR SPEC, Thermofisher, USA). The FTIR spectra were recorded from 400 to $4400 \mathrm{~cm}^{-1}$ with a resolution of $4 \mathrm{~cm}^{-1}$.

\subsubsection{Microscopic observations}

The shape and surface morphology of the glasses and also the formation of hydroxyapatite layer on the surface of the samples after soaking in SBF solution was evaluated using scanning electron microscope (SEM) (Tescan, Vega ts5136MM, CZ). The samples were coated before microscopy by a gold layer.

\subsubsection{Particle size analysis}

The particle size distribution of the powders was determined using a laser particle size analyzer device (Mastersizer 2000, Malvern Instruments, UK).

\subsection{Bioactivity assessment}

For bioactivity assessment of the samples, a simulated body fluid (SBF) was prepared according to the method described by Kokubo and Takadama [40]. Briefly, $75 \mathrm{mg}$ of each sample was immersed in $50 \mathrm{ml}$ of the $\mathrm{SBF}$ solution and incubated at $37^{\circ} \mathrm{C}$ on an orbital shaker 
(KS 4000i control, IKA, Germany) at a constant agitation of 60 R.P.M for 8 h, 3, 7 and 14 days. At the end of each time period, $\mathrm{pH}$ was measured and the solutions filtered through medium porosity filter paper $(5 \mu \mathrm{m}$ particle retention, whatman, USA). Finally, the glass powders treated in SBF were rinsed with acetone (Merck, Germany) to stop any further reaction. Any precipitation or changes in the content was observed during the preparation and preservation of this solution. Table II shows the amount of various chemicals used to SBF preparation.

\section{$2.4 \mathrm{pH}$ measurement}

To study the dissolution process of the glass samples, $\mathrm{pH}$ changes were recorded at the end of each incubation time. After $8 \mathrm{~h}, 3,7$ and 14 days, the $\mathrm{pH}$ value of the samples were measured using a universal electronic $\mathrm{pH}$ meter (Hanna, Italy) that was calibrated according to internal standard operating procedures.

\subsection{Cytotoxicity assay}

Human osteosarcoma cell line (SaOS-2) (National Cell Bank, Pasteur Institute) was used to study of biocompatibility of the samples. To do this, we used the standard colorimetric 3-(4,5dimethyl-2thiazolyl)-2,5-diphenyl- 2H-tetrazolium bromide (MTT) assay. In this study, cells were incubated with a conditioned medium containing $4 \mathrm{mg} / \mathrm{ml}$ of each sample (RPMI-1640 medium supplemented with $10 \%$ fetal bovine serum (FBS) and $1 \%$ penicillin/streptomycin) at $37^{\circ} \mathrm{C}$ for 3,5 and 7 days. At the end of each time period, the grown cells in 24 well plates were incubated with the MTT solution $\left(5 \mathrm{mg} / \mathrm{ml}\right.$ ) (Sigma-Aldrich, UK) for $4 \mathrm{~h}$ at $37^{\circ} \mathrm{C}$ in a humidified atmosphere of $5 \% \mathrm{CO}_{2}$. The yellow tetrazolium salt was metabolized by viable cells to purple 
crystals of formazan. The crystals were solubilized in dimethyl sulfoxide solution (DMSO) (Sigma-Aldrich, UK). Finally, optical density (OD) was measured using a spectrophotometer (Synergy HT, BioTek, USA) at $570 \mathrm{~nm}$ wavelength. The cultures without the glass powder were considered as control groups.

\subsection{Cell attachment study}

The morphology of the grown cells on the surface of the samples were observed using SEM. Prior to observation, the cell-seeded BGs were washed with phosphate-buffered saline (PBS) three times and fixed in a solution containing 2.5\% (v/v) glutaraldehyde (Merck, Germany) in $0.1 \mathrm{M}$ PBS for $2 \mathrm{~h}$. Then, the samples were soaked in $0.1 \%(\mathrm{v} / \mathrm{v})$ osmium tetroxide $\left(\mathrm{OsO}_{4}\right)$ (Sigma-Aldrich, UK) in $0.1 \mathrm{M}$ PBS for $30 \mathrm{~min}$, and washed again with PBS. The next step was dehydration of the samples in graded acetone series (30,50, 75 and 100\%) and maintained in 100\% acetone before freeze-drying (BOC Edwards, Crawley, UK) for $6 \mathrm{~h}$. Finally, the BGs containing cells were sputter coated with gold and viewed SEM (tescan, vega ts5136MM, CZ) at accelerating voltage of $15 \mathrm{keV}$.

\subsection{Alkaline phosphates (ALP) activity assay}

The osteogenic potential of the synthesized BGs was evaluated using ALP activity assay. ALP is a byproduct of osteoblast activity that identified as a marker for differentiation and mineralization of osteoblast cells. For this purpose, SaOS-2 cells grown in 6 wells plates incubated with the conditioned medium containing $4 \mathrm{mg} / \mathrm{ml}$ of each sample at three time periods 7, 14 and 21 days. At the defined time periods, the supernatants were removed and the cells were lysed using Tris-Triton buffer (20mM Tris, $0.5 \%$ Triton X100). The cell lysates were incubated 
with ALP solution (para-Nitrophenylphosphate ( $p N P P$ ) Liquid Substrate System, sigma, USA) at $37{ }^{\circ} \mathrm{C}$ for $30 \mathrm{~min}$. After incubation, optical density of the samples was read at $450 \mathrm{~nm}$ using a microplate spectrophotometer (Synergy HT, BioTek, USA). Finally, a standard curve was plotted using $p$-nitrophenol ( $\mathrm{pNP}$ ) to determine ALP concentrations. ALP concentration was normalized to the cell densities obtained using the WST-8 assay.

\subsection{Bone-like mineralization ability}

Formation of mineralized calcium in the cultures was detected using alizarin red $\mathrm{S}$ staining. Calcium mineralization is mostly considered as a marker for late differentiation of osteoblast cells. SaOS-2 cells were cultured in the conditioned medium ( $4 \mathrm{mg} / \mathrm{ml}$ of each sample) supplemented with 10\% FBS and 1\% penicillin/streptomycin (RPMI-1640, Gibco, USA) for 14 days at $37{ }^{\circ} \mathrm{C}$ in humidified air with $5 \% \mathrm{CO}_{2}$. After incubation, the cells were washed using PBS and then fixed in $4 \%$ Paraformaldehyde for $30 \mathrm{~min}$. Next, the cells were stained using $40 \mathrm{mM}$ alizarin red $\mathrm{S}$ solution $(\mathrm{pH}=4.2-4.4)$ for $45 \mathrm{~min}$ at room temperature in the dark. Finally, the cells were extremely washed using distillated water and viewed using an inverted microscope (Olympus, Japan).

\subsection{Statistical Analysis}

The quantitative results from the MTT test and ALP assay were analyzed using one-way ANOVA test followed by Tukey's post hoc test to determine whether there are any differences. $P$ value of less than $0.05(\mathrm{P} \leq 0.05)$ was considered to be statistically significant. 


\section{Results and discussion}

During the last decade, different types of bioactive glasses have been widely studied due to their therapeutic potential in bone repair and regeneration. The use of these biomaterials has become a common practice in the clinical setting and some compositions are commercially available in the market [9]. Current studies have focused on development of BGs with improved ability to induce osteogenesis and angiogenesis activity in vitro and in vivo. For this purpose, several approaches have studied and in most recently some ions such $\mathrm{as}^{2+}$ and $\mathrm{Co}^{2+}$ are added to the basic structure of glasses $[25,30]$. In recent years, an increasing number of studies have focused on using $\mathrm{Sr}^{2+}$ and $\mathrm{Co}^{2+}$ in the fabrication of porous bone tissue engineering constructs [31]. Although these studies provide new information about the effect of $\mathrm{Sr}^{2+}$ and $\mathrm{Co}^{2+}$ in vitro and in vivo, the influence of the simultaneous use of these two ions on osteogenesis is not still well understood. Therefore, the main goal of this study was synthesis of bioactive glasses using these two ions in the composition for the improvement of osteogenesis activity. Using the meltderived method, four different glasses having different composition (Shown in Table.1) were successfully synthesized, in which $\mathrm{Sr}^{2+}$ and $\mathrm{Co}^{2+}$ replaced with $\mathrm{Ca}^{2+}$ in different percentages.

The XRD results indicated that the structure of all the glasses were amorphous before soaking in SBF solution. To study the formation of an apatite-like layer on the glasses' surfaces, the samples were incubated in SBF solution for $8 \mathrm{~h}, 3,7$ and 14 days. As described in detail by Hench[10], bioactive glasses have the ability to bond to native bone tissue through the formation of a hydroxycarbonate apatite (HCA) layer on the glass surfaces, thereby stimulating osteogenesis activity. In our study, the presence of the HCA layer is visible on the samples' surfaces that is consistent with the results of XRD, FTIR analysis. 
The results of bioactivity test $(\mathrm{SBF})$ revealed that the HCA layer was formed on all the samples after three days of incubation. In addition to examining the structural features such as glass-transition temperature, we investigated the biological properties of the samples on the proliferation and activity of human osteosarcoma cells using MTT test, ALP assay and Alizarin red staining, in which no cytotoxic effects were observed. Alkaline phosphatase (ALP) assay was used to evaluate of effect the glasses on osteoblast cell activity and Alizarin red staining was performed to detect bone like nodules. The obtained results revealed that the incorporation of $\mathrm{Sr}^{2+}$ ion to the glass structure promotes the activity of osteoblast cells and incorporation of $\mathrm{Co}^{2+}$ $(0.5 \mathrm{~mol} \%)$ does not have any toxic effect on cells.

The results of differential scanning calorimetry (DSC) exhibited that there are two apparent glass transition temperatures (Tg) for each sample (see Table I), which could be related to separate phosphate rich and silica rich phases as a result of amorphous phase separation (see Fig.1). However, the second apparent Tg was not so marked and changed temperature on going to a larger particle size. This suggests that $\mathrm{Tg} 2$ is not a second $\mathrm{Tg}$ but is associated with the sintering of the fine glass particles during heating in the DSC. By substituting $\mathrm{Sr}^{2+}$ with $\mathrm{Ca}^{2+}$, the glass transition temperature $(\mathrm{Tg})$ shifted to lower temperatures, which is consistent with previous studies [25] and Fredholm et al. [39] has associated this effect with the larger size of $\mathrm{Sr}^{2+}$ cation compared to $\mathrm{Ca}^{2+}$ and the resulting expansion of the glass network. In agreement with previous data the incorporation of $\mathrm{Co}^{2+}$ in the glass structure has no significant effect on the $\mathrm{Tg}$ of the glasses [31].

X-ray diffraction (XRD) patterns of the glasses before and after immersion in SBF are shown in Fig.2 (a-d). The XRD results of the samples before immersion in SBF confirmed that the samples are amorphous. There is a slight shift in the amorphous scattering maxima to lower 
two theta values on substituting $\mathrm{Sr}^{2+}$ for $\mathrm{Ca}^{2+}$ which is expected as a result of the larger size of the $\mathrm{Sr}^{2+}$ cation compared to $\mathrm{Ca}^{2+}$ which was also found by Fredholm et al [39]. Whereas, XRD patterns of the samples immersed in SBF solution showed that an apatite-like layer formed on the surfaces. Several studies have shown that HCA layer formation results in a peak at $2 \theta=30$ $33^{\circ}$ in XRD pattern of materials $[10,41]$. In addition, the $h k l=002$ diffraction line for apatite at approximately $25.8^{\circ}$ is also present. Accordingly, all the glasses have formed an apatite-like phase between $8 \mathrm{~h}$ to 3 days and a broad peak centred at $2 \theta=32^{\circ}$ corresponding to hydroxyapatite formation $(h k l=211$, JCDPS card 9-0432). There was no significant shift in the diffraction lines to lower two theta values on inclusion of strontium in the BG. This may reflect that the level of strontium substitution for calcium in the apatite lattice is low due to the relative low strontium content in the BG and the fact that a lot of calcium to form the apatite comes from the SBF. A new amorphous peak corresponding to silica gel formed as a result of condensation repolymerization of the silica occurs at approximately $2 \theta=26^{\circ}$ after immersion for all the samples. This peak grows in intensity with increasing immersion time for all the BGs.

Fourier transform infrared spectroscopy (FTIR) was performed on the samples before and after the SBF biomineralization study. Fig.3a shows the spectra of the glasses before soaking in SBF and Fig.3b, c shows the spectra after different time periods after immersion. As shown in Fig.3b, c, split bands appear after immersion at about 560 and $600 \mathrm{~cm}^{-1}$ consistent with apatite formation at 7 and 14 days of incubation. The results are in agreement with XRD data showing formation an apatite-like layer on the surfaces [41]. The presence of $\mathrm{Sr}^{2+}$ and $\mathrm{Co}^{2+}$ ions in the glass composition causes a delay in the formation of HCA layer, which was also reported in some previous studies [31]. 
Fig. 4 shows SEM micrographs of the glass powders and give information on the shape and surface morphology of the glass samples before and after incubation in SBF solution. The results of soaking of the BGs in SBF further supported that an apatite-like layer was formed on the surfaces. SEM images of the SBF-immersed BGs are shown in Fig. 4, where HCA layer formation shows a hierarchical progress with regard to apatite layer formation. These results are in accordance with ISO 23317 (Implants for surgery) that states the glass must be bioactive in less than 4 weeks [42].

The results of static light scattering (SLS) analysis exhibited that mean diameter of the synthesized BG powders was $9.2 \mu \mathrm{m}$ and $90 \%$ particle size distribution was around $23.2 \mu \mathrm{m}$, which is in agreement with the observations with the SEM (see Fig. 4). There was no significant variation with glass composition.

The results of $\mathrm{pH}$ changes are shown in Fig.5. As can be seen, there was no significant difference between the glasses at the end of different incubation times of $8 \mathrm{~h}$ and day 3 . While, in day 7 , the highest $\mathrm{pH}$ value was related to the samples containing $\mathrm{Sr}^{2+}$ ion ( $\mathrm{Sr}$ and $\left.\mathrm{Sr}-\mathrm{Co}\right)$. In day 14 , although the highest $\mathrm{pH}$ values were observed in glasses containing $\mathrm{Sr}^{2+}$ and $\mathrm{Sr}^{2+}-\mathrm{Co}^{2+}$, the values of all samples had been closer to each other at earlier times. It is known that the increasing $\mathrm{pH}$ values during the first three days is related to partial dissolution at the glasses' surfaces as a result of the high reactivity of these biomaterials[10]. These events concur with the process of HCA layer formation on bioactive glasses and glass ceramics in which an ion interchange takes place between $\mathrm{Ca}^{2+}$ and $\mathrm{H}_{3} \mathrm{O}^{+}$from the solution in early stages. These interchanges cause an increase in the $\mathrm{pH}$ value that favors the formation of apatite nuclei on the 
silanol groups on the surface. This is an approved procedure about HCA formation on bioactive glass which has been already documented [43].

The results of MTT assay, shown in Fig.6, demonstrate that there is no significant cytotoxicity effect on the cells. The best results were related to $\mathrm{Sr}^{2+}$-containing glasses $(\mathrm{Sr}, \mathrm{Sr}-$ Co) which is in agreement with previous studies indicating SrR promotes osteoblast proliferation $[18,24]$. Along with increasing the incubation time, better cell proliferation rate is visible in $\mathrm{Sr}^{2+}$-containing samples compared with the other groups. This suggests that $\mathrm{Sr}^{2+}$ ions released from the $\mathrm{Sr}^{2+}$-containing samples enhances metabolic activity with SaOS-2 cells more than that caused by the presence of standard glass ions [44]. Our results indicated that the incorporation of $\mathrm{Co}^{2+}$ ion at 0.5 mole $\%$ is not cytotoxic, but this ion at higher concentrations may cause cell toxicity [30].

SEM images showed that the SaOS-2 cells have well attached well to the surface of the samples (see Fig.7). The alkaline phosphatase (ALP) activity of the SaOS-2 cells cultured in the presence of the conditioned media showed that all the samples increased the ALP level. The findings are consistent with the results of other studies indicating bioactive glasses enhance the osteogenic activity through the induction of osteoblast markers like ALP [45]. It has been previously shown that the main components of bioactive glasses such as phosphate, silicon and calcium are able to up-regulate genes related to bone formation [8]. As shown in Fig.8, ALP activity of the $\mathrm{Sr}^{2+}$-containing glasses ( $\mathrm{Sr}$ and $\mathrm{Sr}-\mathrm{Co}$ ) was higher than the other groups. A similar trend was observed in all the groups after 7, 14 and 21 days of incubation. ALP levels in the Srglass group is fairly higher than Sr-Co-glass group which is due to better effect of Sr-glass on cell viability during incubation times and this effects higher production of ALP enzyme[25]. 
The results of Alizarin Red S staining (Fig.9) showed that calcium deposition was visible in $\mathrm{Ca}^{2+}$-containing samples ( $\mathrm{Ca}$ and $\mathrm{Ca}-\mathrm{Co}$ glasses). This was predictable that $\mathrm{Ca}^{2+}$-containing glasses increase calcium deposition in the cultures through increasing the release of calcium ions into the cell culture medium which is in line with previous studies [46].

\section{Conclusion}

In the present study, a series of bioactive glasses containing different amounts of strontium and cobalt elements were successfully synthesized using a melt-derived route. The XRD results showed that all the glasses produced were amorphous. The in vitro studies showed the bone-like apatite formation capability of the glasses and cellular studies revealed that the glasses do not have any cytotoxicity with human osteosarcoma cells (SaOS-2). However, the number of cells reduced in some samples when dissolution rate of calcium, strontium, cobalt ions were higher, as a result of a quick increase in the $\mathrm{pH}$ of the medium The osteogenic properties of the glasses were confirmed by Alkaline phosphatase (ALP) assay and Alizarin Red S staining. It was shown that the $\mathrm{Sr}^{2+}$-containing samples increased ALP enzyme, while the $\mathrm{Ca}^{2+}$-containing samples promote bone nodule formation in vitro. This study also confirmed that the BGs are capable to promote osteogenesis in vitro. To verify potential of the BGs in improvement of bone regeneration and angiogenesis, an in vivo study is currently under investigation and the results will be published as a follow up report to this article.

\section{Acknowledgments}


The research was financially supported by Iran National Science Foundation (INSF) through research Grant No.91058572.

\section{References:}

[1] A.R. Amini, C.T. Laurencin, S.P. Nukavarapu, Bone tissue engineering: recent advances and challenges, Crit Rev Biomed Eng, 40 (2012) 363-408.

[2] C. Myeroff, M. Archdeacon, Autogenous bone graft: donor sites and techniques, J Bone Joint Surg Am, 93 (2011) 2227-2236.

[3] C. Delloye, O. Cornu, V. Druez, O. Barbier, Bone allografts: What they can offer and what they cannot, J Bone Joint Surg Br, 89 (2007) 574-579.

[4] Q. Chen, J.A. Roether, A.R. Boccaccini, Tissue Engineering Scaffolds from Bioactive Glass and Composite Materials, in: N. Ashammakhi, R. Reis, F. Chiellini (Eds.) Topics in Tissue Engineering, American Scientific Publisher, 2008, pp. 1-27.

[5] M.M. Stevens, Biomaterials for bone tissue engineering, Materialstoday, 11 (2008) 18-25.

[6] B. Baroli, From natural bone grafts to tissue engineering therapeutics: Brainstorming on pharmaceutical formulative requirements and challenges, J Pharm Sci, 98 (2009) 1317-1375.

[7] L.L. Hench, Bioceramics: From Concept to Clinic, Journal of the American Ceramic Society, 74 (1991) 14871510 .

[8] L.L. Hench, D.E. Day, Glass and Medicine, International Journal of Applied Glass Science, 1 (2010) $104-117$.

[9] J.R. Jones, Review of bioactive glass: from Hench to hybrids, Acta Biomater, 9 (2013) 4457-4486.

[10] L.L. Hench, J. Wilson, Surface-active biomaterials, Science, 226 (1984) 630-636.

[11] L.C. Gerhardt, A.R. Boccaccini, Bioactive Glass and Glass-Ceramic Scaffolds for Bone Tissue Engineering, Materials, 3 (2010) 3867-3910.

[12] F. Baino, S. Caddeo, G. Novajra, C. Vitale-Brovarone, Using porous bioceramic scaffolds to model healthy and osteoporotic bone, Journal of the European Ceramic Society, 36 (2016) 2175-2182.

[13] L.S. Pryor, E. Gage, C.J. Langevin, F. Herrera, A.D. Breithaupt, C.R. Gordon, A.M. Afifi, J.E. Zins, H. Meltzer, A. Gosman, S.R. Cohen, R. Holmes, Review of bone substitutes, Craniomaxillofac Trauma Reconstr, 2 (2009) 151-160.

[14] F. Baino, How can bioactive glasses be useful in ocular surgery?, J Biomed Mater Res A, 103 (2015) 12591275 .

[15] F. Baino, G. Novajra, V. Miguez-Pacheco, A.R. Boccaccini, C. Vitale-Brovarone, Bioactive glasses: Special applications outside the skeletal system, Journal of Non-Crystalline Solids, 432, Part A (2016) 15-30.

[16] A. Hoppe, N.S. Guldal, A.R. Boccaccini, A review of the biological response to ionic dissolution products from bioactive glasses and glass-ceramics, Biomaterials, 32 (2011) 2757-2774.

[17] S. O'Donnell, A. Cranney, G.A. Wells, J.D. Adachi, J.Y. Reginster, Strontium ranelate for preventing and treating postmenopausal osteoporosis, Cochrane Database Syst Rev, (2006) CD005326.

[18] S. Tournis, Improvement in bone strength parameters. The role of strontium ranelate, J Musculoskelet Neuronal Interact, 7 (2007) 266-267.

[19] E. Bonnelye, A. Chabadel, F. Saltel, P. Jurdic, Dual effect of strontium ranelate: stimulation of osteoblast differentiation and inhibition of osteoclast formation and resorption in vitro, Bone, 42 (2008) 129-138.

[20] R. Mentaverri, M. Brazier, S. Kamel, P. Fardellone, Potential anti-catabolic and anabolic properties of strontium ranelate, Curr Mol Pharmacol, 5 (2012) 189-194.

[21] U. Tarantino, M. Celi, L. Saturnino, A. Scialdoni, I. Cerocchi, Strontium Ranelate and bone healing: report of two cases, Clin Cases Miner Bone Metab, 7 (2010) 65-68.

[22] O. Cebesoy, E. Tutar, K.C. Kose, Y. Baltaci, C. Bagci, Effect of strontium ranelate on fracture healing in rat tibia, Joint Bone Spine, 74 (2007) 590-593.

[23] B. Habermann, K. Kafchitsas, G. Olender, P. Augat, A. Kurth, Strontium ranelate enhances callus strength more than PTH 1-34 in an osteoporotic rat model of fracture healing, Calcif Tissue Int, 86 (2010) 82-89.

[24] J.Y. Reginster, E. Seeman, M.C. De Vernejoul, S. Adami, J. Compston, C. Phenekos, J.P. Devogelaer, M.D. Curiel, A. Sawicki, S. Goemaere, O.H. Sorensen, D. Felsenberg, P.J. Meunier, Strontium ranelate reduces the risk of 
nonvertebral fractures in postmenopausal women with osteoporosis: Treatment of Peripheral Osteoporosis (TROPOS) study, J Clin Endocrinol Metab, 90 (2005) 2816-2822.

[25] E. Gentleman, Y.C. Fredholm, G. Jell, N. Lotfibakhshaiesh, M.D. O'Donnell, R.G. Hill, M.M. Stevens, The effects of strontium-substituted bioactive glasses on osteoblasts and osteoclasts in vitro, Biomaterials, 31 (2010) 3949-3956.

[26] N. Lotfibakhshaiesh, D.S. Brauer, R.G. Hill, Bioactive glass engineered coatings for Ti6Al4V alloys: Influence of strontium substitution for calcium on sintering behaviour, Journal of Non-Crystalline Solids, 356 (2010) 25832590.

[27] M.W. Laschke, Y. Harder, M. Amon, I. Martin, J. Farhadi, A. Ring, N. Torio-Padron, R. Schramm, M. Rucker, D. Junker, J.M. Haufel, C. Carvalho, M. Heberer, G. Germann, B. Vollmar, M.D. Menger, Angiogenesis in tissue engineering: breathing life into constructed tissue substitutes, Tissue Eng, 12 (2006) 2093-2104.

[28] K. Lin, L. Xia, H. Li, X. Jiang, H. Pan, Y. Xu, W.W. Lu, Z. Zhang, J. Chang, Enhanced osteoporotic bone regeneration by strontium-substituted calcium silicate bioactive ceramics, Biomaterials, 34 (2013) 10028-10042. [29] E. Quinlan, S. Partap, M.M. Azevedo, G. Jell, M.M. Stevens, F.J. O'Brien, Hypoxia-mimicking bioactive glass/collagen glycosaminoglycan composite scaffolds to enhance angiogenesis and bone repair, Biomaterials, 52 (2015) 358-366.

[30] C. Wu, Y. Zhou, W. Fan, P. Han, J. Chang, J. Yuen, M. Zhang, Y. Xiao, Hypoxia-mimicking mesoporous bioactive glass scaffolds with controllable cobalt ion release for bone tissue engineering, Biomaterials, 33 (2012) 2076-2085.

[31] M.M. Azevedo, G. Jell, M.D. O'Donnell, R.V. Law, R.G. Hille, M.M. Stevens, Synthesis and characterization of hypoxia-mimicking bioactive glasses for skeletal regeneration, Journal of Materials Chemistry, 20 (2010) 88548864.

[32] A. Namiki, E. Brogi, M. Kearney, E.A. Kim, T. Wu, T. Couffinhal, L. Varticovski, J.M. Isner, Hypoxia induces vascular endothelial growth factor in cultured human endothelial cells, J Biol Chem, 270 (1995) 31189-31195.

[33] W. Fan, R. Crawford, Y. Xiao, Enhancing in vivo vascularized bone formation by cobalt chloride-treated bone marrow stromal cells in a tissue engineered periosteum model, Biomaterials, 31 (2010) 3580-3589.

[34] X. Hu, S.P. Yu, J.L. Fraser, Z. Lu, M.E. Ogle, J.A. Wang, L. Wei, Transplantation of hypoxia-preconditioned mesenchymal stem cells improves infarcted heart function via enhanced survival of implanted cells and angiogenesis, J Thorac Cardiovasc Surg, 135 (2008) 799-808.

[35] H.H. Kim, S.E. Lee, W.J. Chung, Y. Choi, K. Kwack, S.W. Kim, M.S. Kim, H. Park, Z.H. Lee, Stabilization of hypoxia-inducible factor-1alpha is involved in the hypoxic stimuli-induced expression of vascular endothelial growth factor in osteoblastic cells, Cytokine, 17 (2002) 14-27.

[36] J. Malda, T.J. Klein, Z. Upton, The roles of hypoxia in the in vitro engineering of tissues, Tissue Eng, 13 (2007) 2153-2162.

[37] K. HJ, Hypoxic regulation of osteoclast differentiation and bone resorption activity, Hypoxia, 3 (2015) 73-82.

[38] T. Tanaka, I. Kojima, T. Ohse, J.R. Ingelfinger, S. Adler, T. Fujita, M. Nangaku, Cobalt promotes angiogenesis via hypoxia-inducible factor and protects tubulointerstitium in the remnant kidney model, Lab Invest, 85 (2005) 1292-1307.

[39] Y.C. Fredholm, N. Karpukhina, D.S. Brauer, J.R. Jones, R.V. Law, R.G. Hill, Influence of strontium for calcium substitution in bioactive glasses on degradation, ion release and apatite formation, J R Soc Interface, 9 (2012) 880-889.

[40] T. Kokubo, H. Takadama, How useful is SBF in predicting in vivo bone bioactivity?, Biomaterials, 27 (2006) 2907-2915.

[41] R.A. Martin, H. Twyman, D. Qiu, J.C. Knowles, R.J. Newport, A study of the formation of amorphous calcium phosphate and hydroxyapatite on melt quenched Bioglass using surface sensitive shallow angle X-ray diffraction, $\mathrm{J}$ Mater Sci Mater Med, 20 (2009) 883-888.

[42] ISO22317, Implants for surgery - In vitro evaluation for apatite-forming ability of implant materials. , International Standard ISO/FDIS, 23317 (2012).

[43] W. Huang, D.E. Day, K. Kittiratanapiboon, M.N. Rahaman, Kinetics and mechanisms of the conversion of silicate (45S5), borate, and borosilicate glasses to hydroxyapatite in dilute phosphate solutions, J Mater Sci Mater Med, 17 (2006) 583-596.

[44] G. Jell, M.M. Stevens, Gene activation by bioactive glasses, J Mater Sci Mater Med, 17 (2006) 997-1002.

[45] S.A. Oh, S.H. Kim, J. Won, J.J. Kim, U.S. Shin, H.W. Kim, Effects on Growth and Osteogenic Differentiation of Mesenchymal Stem Cells by the Zinc-Added Sol-Gel Bioactive Glass Granules, Journal of Tissue Engineering, 2010 (2010) 1-10. 
[46] J.E. Gough, J.R. Jones, L.L. Hench, Nodule formation and mineralisation of human primary osteoblasts cultured on a porous bioactive glass scaffold, Biomaterials, 25 (2004) 2039-2046. 